\title{
Covid-19 and nursing workforce, leadership and education development - a discussion paper
}

\author{
Sally Wai-chi Chan ${ }^{1}$ \\ ${ }^{1}$ Pro Vice-Chancellor, Deputy Director, Priority Research Centre for Brain and Mental Health, \\ Faculty of Health and Medicine, The University of Newcastle, Australia
}

\begin{abstract}
The year 2020 was intended to be a celebratory year for all nurses and midwives as the World Health Organisation has designed it to be the International Year of the Nurse and the Midwife. With the coronavirus (COVID-19) pandemic sweeping through the globe, 2020 has turned out to be a year that is entirely different from what nurses expected. Drawing from contemporary literature and first-hand experience as an academic working in higher education institution, this paper discusses the unique challenges and opportunities that nursing profession faced in the COVID-19 pandemic. It examines the impact of this pandemic on nursing workforce, leadership and education in the year 2020 and beyond.
\end{abstract}

\section{KEY WORDS}

COVID-19 pandemic; Nursing Leadership; Nursing workforce; Nursing Education

\section{INTRODUCTIONS}

Nurses are backbones of healthcare system. There are about 27.9 million nurses worldwide, they make up more than half the global healthcare workforce (1). The year 2020 has been designated by the World Health Organisation (WHO) as the International Year of the Nurse and the Midwife. It is in honor of the 200th anniversary of Florence Nightingale's birth; in recognition of the contributions that nurses and midwives make; and the risks associated with nursing shortages (2).

The 2020 is also an unprecedent year when most parts of the world has been affected by the novel coronavirus pandemic (COVID-19). Since the first time a patient with pneumonia of unknown cause in $\mathrm{Wu}-$ han, China was reported to the WHO's China office on 31 December 2019 (3), there were now over 25 million confirmed positive cases of COVID-19 globally, and 844,695 reported in death as of 31 Aug 2020 (4). This pandemic has impacted almost everything in the world from the way we communicate, live, work, study, and travel to the way of doing business, manufacturing, and running a community or a country. While the world economy is suddenly shaken to its foundations, the healthcare systems of many countries are also stretched to their limits within a very short time.

Nurses are right at the frontline of the response to the pandemic. Catton (5) commented that since the days of Florence Nightingale, nurses have been making huge contributions to caring for victims of war, famine, natural disasters, and public health crisis. In recent decades, the world has seen frequent outbreaks of infectious diseases such as H1N1, Swine Flu, Ebola, severe acute respiratory syndrome (SARS). This COVID-19 pandemic again brings to global awareness of the important role and contributions of nurses. Nurses are vital for managing the COVID-19 pandemic in both hospitals and communities. It reminds the world that adequate number of well educated, properly trained and highly committed nurses are critical to any healthcare system (5).

Drawing from contemporary literature and firsthand experience as academic working in higher education institution (HEI), this paper discusses the unique challenges and opportunities that nursing profession faced in the COVID-19 pandemic. It examines the impact of this pandemic on nursing workforce, leadership and education and the implications of this pandemic to future nursing development as we progress to the new normal.

\section{Nursing workforce challenges}

Nursing workforce has been central to COVID-19 response effectiveness in all countries. Nursing shortages have already an embedded challenge before COVID-19. A report published by the International 
Council of Nurses (ICN) estimated a global shortage of 5.9 million nurses this year. Nursing shortage could undermine present and future responsiveness to pandemics, as well as broader health system effectiveness (1).

COVID-19 pandemic could have positive and negative impacts on nursing workforce development. Catton (5) commented that the COVID-19 pandemic has changed the way the public perceive nurses. The comforting images of nurses in traditional uniforms have been replaced by images of intensive care nurses in full personal protective equipment (PPE). Social media across the world have shown photographs of exhausted nurses with bruises on their faces caused by wearing N95 facemask for long hours. Such realistic portray might help the public became more aware of the challenges, complexity and hardships of nursing work during the COVID-19 pandemic and beyond. Some people might respond positively to the impressive images of nurses. They might want to support nurses for their hard work. Some might even consider joining the nursing profession (5). An interview with applicants of nursing program in the United Kingdom (UK) found that the applicants regarded the pandemic and response to nurses by the public has positively reinforced their choice of career (6).

However, the image of nurses taking risk to care of patients infected with COVID-19 has unfortunately turned against the nurses in some communities. The fear of nurses becoming carriers and spreading the virus had led to discrimination, abusive behaviour and even violence against nurses and other healthcare workers (7).

Nurses are right at the frontline of the response to the pandemic. Like other healthcare professionals, nurses are facing challenges of insufficient information, shortage of appropriately trained critical care nurses, inadequate PPE, moral distress, and high risk of being infected by the COVID-19 (8). In the face of the COVID-19 pandemic, nurses do what they can to care for the patient, but not without fear. Fernandez, et al.s (9) systematic review highlighted the fear and vulnerability of nurses during pandemic. The review identified that most nurses, regardless of the circumstances, felt a great sense of professional duty to work during a pandemic. However, one of their main fears was spreading the infection to their family members, particularly the elderly, and young children. Many nurses isolated themselves even when they were at home. They avoided joining the family for meals or visiting their older parents or hugging and kissing the spouse and kids (9).

In caring for a large number of critically ill patients suffering from COVID-19, rationing of re- sources cannot be avoided. Apart from equipment, nurses also rationed their time for person-to-person engagement. Some nurses felt powerless as they had no choice but to ration the care by giving more time and attention to the critically ill patients. It is another main concern for the nurses and was a source of their stress and anxiety (9).

The growing concerns about the difficulties experienced by nurses have implications to future workforce. COVID-19 has exposed the vulnerability of nursing shortage. In the UK, an alarming $36 \%$ of respondents to a survey conducted by the Royal College of Nursing (RCN), expressed that they considered leaving the profession, mostly related to the pay, not valued by the government, how they were being treated during the COVID-19 pandemic, lack of management support and low staff level (10). Actions are needed from policy maker and nurse leaders to overcome these concerns.

The United Nation (UN) recommended an urgent need to have adequate communication for the public as well as specific measures to be put in place to protect nurses and healthcare professionals in response to the current pandemic (11). Both the government and healthcare leaders need to address abusive behavior towards nurses and other healthcare professionals. Education for the public and appropriate law enforcement actions should help to protect nurses to ensure their safety while devoting themselves to care for those infected with COVID-19.

Most nurses need support from their colleagues, their organisation and families to cope with emotional difficulties. To manage their stress and anxiety, some nurses coped by immersing themselves in patient care. Professional camaraderie was found to be high and helpful during crisis (9). A study in China suggested hospitals to provide more psychological support to nurses, adopt better training in coping strategies, arrange for adequate medical protective equipment, and develop a broad range of interventions to block the spread of infectious diseases so as to form a safe environment where COVID-19 would not spread in hospitals. This would create an optimistic environment and guarantee the personal safety of nurses, thereby enabling them to carry on with the highest quality of patient care (12). ICN (13) recommended that governments should protect the health and wellbeing of nurses and other healthcare workers through providing access to mental health and counselling resources. COVID-19 exposure in the workplace is considered occupational exposure and the resulting illness would be considered an occupational disease. Governments should ensure compensation, 
curative services and rehabilitation are provided for infected health workers (13).

Longer term strategies need to be in place to increase recruitment and retention, such as pay reviews and increasing opportunities for educating next generation of nurses. In the UK, the RCN is actively pursuing with the government to work on solution for recruiting and retaining nurses. Together with 13 other unions, the RCN has sent an open letter to prime minister and chancellor asserting that pay must be enough to attract and retain nurses (14). Buchan and Catton (1) commented that as nine out of every ten nurses worldwide are female. Thus there is a need to develop or review nurse workforce policies and implementation to have an overarching objective of creating decent work for women and closing gender gaps in leadership and pay. Each country must have a country level policy change related to nursing workforce with support from international nursing organisations.

There has been a call from ICN for the rapid expansion of the number of Registered Nurses and other practitioners, including expediting nursing student graduation or recalling retired nurses. This can be effectively supported by National Nurses Associations (NNA), which have the expertise to ensure that any expansion of the workforce is robust and approached strategically with an aim to maintain a competent and capable workforce (13).

Nurse leaders in the crisis of COVID-19 pandemic A decade back in time, the Institute of Medicine (15) (renamed as National Academy of Medicine now) proposed a reform of nursing leadership. It recommended that future nurses should be full partners with physicians and other health professionals in redesigning health care. The IOM report calls for nurses to assume primary responsibility for personal and professional growth through continuing education and opportunities that advance their leadership skills (16).

Progresses have been made on nursing leadership development since the IOM report. For example, across the globe, leadership training is now an integral part of many undergraduate, postgraduate as well as continuing nursing education programs to ensure leadership skills are learned and mastered. Clinical leadership roles, such as Clinical Nurse Leaders (CNLs) have been well established in the USA, with clear role descriptions and responsibilities which are linked to the funding system (3). However, in relation to high-level health policy decision-making, nurses are often missing even when issues directly affect nurses and nursing $(3,8)$.
The pandemic has exposed some deep-rooted difficulties in today's nursing leadership. As frontline healthcare professionals, nurses should have valuable expertise and perspectives to offer in the COVID-19 response. But nurses do not have a strong voice in this pandemic. Nursing leadership is not visible. Nurses' concerns have not been well addressed, and nurses' unique contributions to healthcare system have not been fully utilized $(3,8,17)$. For example, in the USA, there are approximately 4 million registered nurses, but the current White House Coronavirus Task Force does not include any nurses, nor do most state or local coronavirus response teams (3).

To respond adequately to the pandemic, Hoffman, et al. (3) advocated that nurses should be added to all health-related commissions, panels, and task forces. It is because nurses' work is diverse and spans the care of individuals, families, groups, communities, and populations of all ages across the lifespan. Nurses unique insights into patient care can benefit healthcare resource allocation decisions, and infection prevention measures in hospitals and communities. Further, nurses' in-depth knowledge of patients' holistic needs would help policymakers consider all the implications of the pandemic and where resources are needed. In addition, nurses are the health professionals the public views as the most ethical and trustworthy $(3,8)$. It is thus important to have nurses' presence at high level health policy decision-making tables.

The COVID-19 pandemic has indeed highlighted the need to strengthen nursing leadership's visibility and involvement in health policy formulation and decision-making, as well as contributing to the effectiveness of health and social care systems (18). To be effective leaders and full partners, IOM (15) has recommended a decade ago that nurses need to possess critical sets of competencies which included knowledge of the care delivery system, how to work in teams, how to collaborate effectively within and across disciplines, the basic tenets of ethical care, how to be an effective patient advocate, theories of innovation, and the foundations for quality and safety improvement. Such competencies can serve as the foundation for any leadership opportunity. Nurses need to learn how to be a full partner in a health team in which members from various professions hold each other accountable for improving quality. Additionally, nurses who are interested in pursuing entrepreneurial and business development opportunities need competencies in such areas as economics and market forces, regulatory frameworks, and financing policy $(15,16)$. IOM's recommendations continue to be relevant for today's nursing leadership development. 
It is important to identify how to drive the voices and decision making of nursing leaders. ICN recommended that ICN's 130-plus NNAs, represent nursing communities in every region of the globe, are the repository of decades of knowledge and experience. Governments should see NNAs as key partners to provide expertise and advice at the highest level of policymaking. Further, Rosser, et al. (17) advocate an international panel of nurse leaders to debate how to offer a more collaborative and inclusive approach to decision making when the world encounters future waves of infection and future global challenges to nursing, healthcare delivery, and systems. In addition, there is an urgent need for nursing bodies and healthcare organisations to accelerate their commitment in providing leadership development, mentoring programs, and opportunities for nurses $(16,17)$.

\section{Nursing education - to cope or to transform?}

The requirement for social distancing during the COVID-19 pandemic has caused disruption to the operations of education institutions at all levels. In most parts of the world today, nursing schools are a part of HEIs with domestic and international students, both are affected by travel restriction, social distancing, isolation and quarantine measures.

The sudden mandatory closure of campuses has forced educators of all disciplines to switch teaching and assessments entirely from in-person to the online mode. The global adoption of online solutions since the start of COVID-19 pandemic in January 2020 has been unprecedented. In the short term, online learning is regarded as a 'first aid' solution for many institutions. In the longer term, online learning may stay and continue to develop.

Some educators may have concern that online education does not provide human interactions that are needed. However, others may take a different view. When compared to lecturing 500 students in a lecture theatre, some teachers who adopt online teaching may find that they can have more engagement with the students in the online Zoom session. For students, online learning could be more flexible as they could learn in anywhere and anytime they like. In the personal experience of the author, some students expressed that they had more attention from their teachers via Zoom than in a big group in a lecture theatre. They could ask questions via real time chat. All lectures/interactions could be easily recorded for necessary follow-up learning. After experiencing the flexible, active and responsible teaching and learning through online platform, some teachers and students may start appreciating that online flexibility is critical for the sustainment of higher education. A recent survey conducted in Hong Kong $(n=69)$ found that many nurse educators $(71 \%)$ were confident in delivering nursing courses online. They were mostly satisfied in content delivery and engaging students in learning through online teaching (19). Another survey of 56 nursing students in Hong Kong who engaged in an online course during the COVID-19 pandemic found that $48 \%$ of the students showed high learning engagement in the course (20). Though the samples were small in the above-mentioned studies, they demonstrated the possibilities to further explore the potential of online learning.

The COVID-19 pandemic has made digital literacy an essential, not only in education, but in all walks of life. After the pandemic, greater digitalization of services and more digitally centered communications could be the future norm. Fundamentally, the pandemic is causing us to challenge deep-rooted notions of when, where, and how we deliver nursing education, and of the role of HEIs.

At the time of writing this paper, many HEIs have carefully started reopening the campus with many precautionary restrictions put in place. Some classroom and laboratory learning are available for small group teaching while safe distancing and other infection control measures are maintained. But online teaching will continue to become an integral part of education. Moving forward, it is expected that pedagogy would become more blended than ever. A given class may contain a mix of in-person and remote students and educators. There will surely be a move to a greater use of technology, be it synchronous, asynchronous, or virtual. More educators will upskill themselves in this hybrid space. A blended or hybrid mode of remote learning will become the new normal. Some of the partnerships developed between HEIs and education technology providers during the COVID-19 pandemic will continue to grow because of the actual and strong needs. Also, technologies will continue to improve and update to enhance teaching and learning experience.

Clinical placement is an essential component of the nursing curriculum. Nursing students must meet the requirement for clinical placement hours as stipulated by the national regulatory body. There remain many challenges to overcome during the pandemic to provide a safe and conducive clinical learning environment. Nursing schools must protect students from COVID-19 infection, but at the same time, to ensure nursing students fulfilling the accreditation requirements, and graduating on time to provide steady supply of nursing workforce to healthcare systems (21). 
In some countries, students had to withdraw from clinical practicums, while in some, the clinical training capacities in healthcare settings have drastically reduced which made it difficult to arrange adequate clinical experience for students. For students who have opportunities for clinical placement, nurse educators may have concern about their safety. For example, students are in high risk if they practise in a facility without adequate PPE, or the structure is not properly built for admitting patients with the COVID-19 infection. Students may volunteer to take the risk to complete the clinical placement requirement and get their nursing qualification. Such risk must be calculated, and stringent precautionary measurement be taken (21).

In the UK, special placement opportunities are offered to year two and three nursing students. They could sign up to undertake extended placements in health and social care organisations. The students who take up such extended placement opportunity would be remunerated in line with the salaries of nursing care assistants. Students have to consider various factors in deciding where to take up this extended placement. such as their desire to help, their need to earn, their health, the health of their families, anxiety about the quality of the learning experience and a desire to complete their program on time. An interview with students found those who were willing to take the extended placement expressed a sense of being part of history, learning new things, and stepping up to a challenge that would be personally fulfilling as well as professionally worthwhile. Students who could not take this opportunity because of various reasons might have a sense of failure (6).

While students have to make difficult decision, nursing schools should work closely with the clinical partners to ensure that students are making a free choice. They both have a duty of care to ensure the physical and psychological safety of nursing students. They must work out how best to protect the students while the clinical experience is relevant and necessary. Students' competency of managing the infection risk and willingness must be verified, and sufficient supervision be assured $(6,21)$.

In response to the challenges in providing relevant clinical experiences and skills training during the pandemic, there are increasing development and use of simulation, telehealth and virtual reality (VR)(22). There are possibilities of using technology to provide meaningful clinical experiences and skills training in addition to experiences of in person contact. Telehealth would become more acceptable and use more often after the pandemic. The use of VR and high-fidelity simulation experiences is helpful to bridge the gap between theory and practice. Nurse educators and clinical partners can work together to generate realistic, lively, individualized, and frequently updated scenarios in the simulation learning environment. It could also be timely for regulatory bodies to recognise some percentage of clinical experiences that are delivered via telehealth, high fidelity simulation, VR or other types of technology. Rigorous research should be conducted to evaluate student learning outcomes for new initiatives to ensure the quality of nursing education will continue to improve during the pandemic and beyond (22).

\section{CONCLUSION}

At the time of writing this paper, the COVID-19 pandemic is continuing across the globe. The world is still developing the best treatment and vaccine for the COVID-19. The pandemic is a true test of human being's potential to survive, adapt and sustain. Nurses' response to the COVID-19 pandemic worldwide demonstrates their ongoing courage and dedication. Nurses continue contributing to the health and wellbeing of the society. People joining the nursing profession in the years to come would be inspired by those nurses risking their lives to care for those infected by the COVID-19. This paper highlights some current challenges and opportunities in nursing workforce, leadership and education. Regular reflection on nursing professional issues could help to find the best way forward. It could be the right thing to do in memory of Florence Nightingale's legacy and to celebrate the International Year of the Nurse and the Midwife.

\section{REFERENCES}

1. Buchan J, Catton H (2020). COVID-19 and the International Supply of Nurses. Report for the International Council of Nurses. Geneva: International Council of Nurses.

2. World Health Organisation [Internet]. Year of the Nurse and the Midwife 2020; [cited 2020 Aug 20]. Available from: https://www.who.int/campaigns/ year-of-the-nurse-and-the-midwife-2020.

3. Hoffman RL, Battaglia A, Perpetua Z, Wojtaszek K, Campbell G. The Clinical Nurse Leader and COVID-19: Leadership and quality at the point of care. Journal of Profesional Nursing. 2020; 36(4):178-180. doi: 10.1016/j.profnurs.2020.06.008.

4. Johns Hopkins University of Medicine Coronavirus Research Centre [Internet]. Coronavirus Dashbord [cited 2020 Aug 31]. Availbable from: https://coronavirus.jhu.edu/map.html.

5. Catton $H$ [Internet]. Nursing after COVID-19: the long-term impact of our high-profile role. Nursing Standard. 2020 August 4. Retrieved on 
20 August 2020 from: https://rcni.com/nursing-standard/opinion/comment/nursing-aftercovid-19-long-term-impact-of-our-high-profilerole-164071.

6. Swift A, Banks L, Baleswaren A, Cooke N, Little C, McGrath L et al. COVID-19 and student nurses: A view from England. Journal of Clinical Nursing. 2020; 29(17-18):3111-3114. doi: doi.org/10.1111/ jocn. 15298.

7. Kendall-Raynor P. Protection demanded for nurses 'ostracised and abused' during pandemic worldwide. Nursing Standard [Internet]. 202021 May [cited 2020 Aug 20]. Available from: https://rcni.com/nursing-standard/news$\mathrm{room} /$ news/protection-demanded-nurses-ostracised-and-abused-during-pandemic-worldwide-161311.

8. Daly J, Jackson D, Anders R, Davidson P. Editorial - Who speaks for nursing? COVID-19 highlighting gaps in leadership. Journal of Clinical Nursing. 2020; 29(15-16):2751-2752. doi: 10.1111/ jocn. 15305.

9. Fernandez R, Lord H, Halcomb E, Moxham L, Middleton R, Alananzeh I, Ellwood L. Implications for COVID-19: a systematic review of nurses' experiences of working in acute care hospital settings during a respiratory pandemic. International Journal of Nursing Studies. 2020; 111(2020):103637. doi: doi.org/10.1016/j.ijnurstu.2020.103637

10. Hackett K. More than a third of nurses are thinking of quitting - and low pay is the main reason. Nursing Standard [Internet]. 202017 Jul [cited 2020 Aug 20]. Available from: https://rcni.com/ nursing-standard/newsroom/news/more-a-thirdof-nurses-are-thinking-of-quitting-and-low-paymain-reason-163431.

11. UN News [Internet]. COVID-19 highlights nurses' vulnerability as backbone to health services worldwide. 2020; [cited 2020 Aug 30]. Available from: https://news.un.org/en/story/2020/04/1061232.

12. Huang L, Lei W, Xu F, Liu H, Yu L. Emotional responses and coping strategies in nurses and nursing students during Covid-19 outbreak: A comparative study. PLoS ONE. 2020; 15(8):e0237303. doi: https://doi.org/10.1371/journal.pone.0237303.

13. International Council of Nurses [Internet]. Nursing Standard [Internet]. ICN Call for Action. COVID-19. Geneva: ICN [cited 2020 Aug 31]. Available from: https://www.icn.ch/system/ files/documents/2020-04/ICN\%20briefing COVID19_Top_priorities_ENG.pdf.

14. Hackett K. Nurses need new pay deal not COVID bonus, PM told. Nursing Standard [Internet].
202003 Jul [cited 2020 Aug 20]. Available from: https://rcni.com/nursing-standard/newsroom/ news/nurses-need-new-pay-deal-not-covid-bonus-pm-told-162966.

15. Institute of Medicine (US) Commmittee on the Robert Wood Johnson Foundation Initiative ofn the Future of Nursing, at the Institute of Medicine. Washington (DC): National Academies Press (US); 2011.

16. Porter-O'Grady T. Future of nursing special: Leadership at all levels. Nursing Management. 2011 42(5):32-37.

17. Rosser E, Westcott L, Parveen AA, Bosanquet J, Castro-Sanchez E, Dewing J, McCormack B, Merrell J, Witham G. The need for visible nursing leadership during COVID-19. Journal of Nursing Scholarship. 2020; 52(5):459-461. doi: doi. org/10.1111/jnu. 12587.

18. World Health Organisation (2020). State of the world's nursing 2020: investing in education, jobs and leadership. Geneva: WHO.

19. Hong Kong Society for Nursing Education (HKSNE). HNSNE nursing education survey report. HKSNE Newsletter [Internet]. 2020 Aug [cited 2020 Aug 31]: 4-6 pp. Available from: http:// www.hksne.org.hk/sharefiles/Newsletter_August\%202020_HKSNE.pdf.

20. Chan P. Enhancing online learning engagement of nursing students- A pilot study. HNSNE nursing education survey report. HKSNE Newsletter [Internet]. 2020 Aug [cited 2020 Aug 31]: 7 p. Available from: http://www.hksne.org.hk/sharefiles/ Newsletter_August\%202020_HKSNE.pdf.

21. Dewart G, Corcoran L, Thirsk L, Petrovic K. Nursing education in a pandemic: Academic challenges in response to COVID-19. Nurse Education Today. 2020; 92(2020):104471. doi: 10.1016/j. nedt.2020.104471.

22. Morin K. Editorial - Nursing education after COVID-19: Same or different. Journal of Clinical Nursing. 2020; 29(17-18):3117-3119. doi: 10.1111/ jocn. 15322 .

\section{HLAVNÍ AUTOR}

\section{Sally Wai-chi Chan, PhD, RN, FAAN}

Priority Research Centre for Brain and Mental Health

Faculty of Health and Medicine

The University of Newcastle (UoN) Singapore

6 Temasek Boulevard, \#10-02/03, Suntec Tower 4, Singapur 038986

sally.chan@newcastle.edu.au

+6562213306 